\title{
Symbol Search Subtest (WISC-V)
}

National Cancer Institute

\section{Source}

National Cancer Institute. Symbol Search Subtest (WISC-V). NCI Thesaurus. Code

C120362.

A subtest of the Wechsler Intelligence Scale for Children, Fifth Edition. The subject scans a search group and indicates whether one of the symbols in the target group matches. 